\title{
Identifying and describing the knowledge needed by teachers of mathematics
}

\author{
Peter Sullivan
}

Published online: 26 May 2011

(C) Springer Science+Business Media B.V. 2011

This editorial is my final contribution to the Journal of Mathematics Teacher Education as an editor. I have been an associate editor for 5 years and editor for over 3 years. It has been a privilege to contribute to the discipline of mathematics teacher education in this way and to follow the footsteps of the previous editors, Professor Tom Cooney and Professor Barbara Jaworski. I thank them both for their confidence in me and their encouragement. I am also delighted to be handing over to Professor Olive Chapman, who has now been managing the manuscripts and reviewing process for all of this year, knowing that the journal will develop and grow under Olive's leadership.

As Barbara outlined in her final editorial (Jaworski 2007), the discipline of mathematics teacher education is now well established and the recent four volume International Handbook of Mathematics Teacher Education is further evidence of the substantial research and scholarship being conducted into the education of teachers of mathematics.

While approaches to mathematics teacher learning differ from context to context and culture to culture, the knowledge that teachers need is at the centre of initiatives to improve mathematics education everywhere. Offering experiences that enhance this knowledge remains the major consideration of those preparing programs for teachers of mathematics, and research on that knowledge is of great interest. It is opportune that the articles in this issue focus particularly on knowledge for teaching mathematics.

A useful categorisation that can assist in describing the knowledge that teachers need was proposed by Hill et al. (2008). Building on the well-known work of Shulman (1986), they proposed two categories of knowledge: subject matter knowledge; and pedagogical content knowledge. In their diagrammatic model, subject matter knowledge is made up of three sub-categories: common content knowledge; specialised content knowledge; and knowledge at the horizon. Pedagogical content knowledge is made up of: knowledge of content and teaching; knowledge of content and students; and knowledge of curriculum.

In Australia, children from ages 5-11 are grouped in one type of school with teachers who are generalist, meaning they teach every subject. While teacher education programs include some aspects of mathematics and mathematics education, those teachers

P. Sullivan $(\bowtie)$

Monash University, Melbourne, Australia

e-mail: peter.sullivan@education.monash.edu.au 
predominantly draw on the mathematics they learned themselves at primary and secondary school and rely on various resources and on-going teacher learning opportunities to assist them in their teaching. Teachers of students aged 12-17 (in secondary schools) are taught by specialised mathematics teachers who have ideally studied a sequences of mathematics course at university level. Those teachers often rely on text materials and other resources to support them in their teaching. The knowledge those teachers have and experiences to enhance that knowledge are the focus of teacher education initiatives everywhere.

More recently, due to a shortage of applicants for teaching positions who have studied mathematics at university level, there are now many teachers of mathematics in secondary schools in Australia who are not specialists in mathematics teaching. This raises an extreme situation that has potential to shed light on the overall challenge of developing the knowledge of teachers of mathematics. While many teachers with limited post-school studies in mathematics build productive relationships with students and are experienced at managing classes, not only have they not studied mathematics at university level but also they may not have enjoyed their mathematics while at school given that they pursued other studies at university. Clearly, it is not possible for such teachers to learn all the mathematics that more conventionally prepared teachers have learned, given that their main teaching interest is in science, or music, or something else. But, they do need to know the mathematics they are teaching, as well as how to teach it. Otherwise, there is some risk that their contribution to the mathematics learning of their students might be negative.

Perhaps the issue of nonspecialist teachers is a problem idiosyncratic to Australia, but it raises questions that apply to all teachers. What is the appropriate level of knowledge of the concepts and procedures that form the basis of mathematics learning at school and what is the appropriate knowledge of what it is to do mathematics? Such teachers with limited knowledge of the mathematics need access to support on aspects of mathematics that may be unfamiliar to them, an orientation to learning the mathematics that may be needed, and pedagogies that allow teachers and students to explore mathematical ideas together with less expectation that the teacher is the one who knows everything. As it happens, all teachers of mathematics need such support. The articles in this issue provide important and detailed insights into the elements of knowledge for teaching mathematics.

In the article 'Using comparison to develop flexibility for teaching algebra', Christopher Yakes and Jon Star report a teacher learning initiative that focused on using comparison to develop flexibility in interpreting algebra, with emphasis on the potential of using multiple solution methods as an instructional tool. Using the language of Hill et al., awareness of existence of multiple possible solution pathways and interest in exploring them is an aspect of specialised content knowledge. The article also addresses components related to the teaching of algebra that relate to the knowledge of content and teaching.

Colleen Vale, Alasdair McAndrew and Siva Krishnan in their article 'Connecting with the horizon: Developing teachers' appreciation of mathematical structure', describe an initiative to teach mathematics to teachers working in junior secondary classes who were interested in teaching mathematics in the senior years but had little prior study in mathematics. Their focus was on developing connections and emphasizing mathematical structure. These mathematical structures can be described as common content knowledge, but the connections are specialised content knowledge. The approaches to thinking mathematically can be described as knowledge at the horizon.

In the article 'The nature of prospective mathematics teachers' pedagogical content knowledge: The case of multiplication of fractions', Mine Isiksal focuses on students' common conceptions and misconceptions and on ways of overcoming them. Their focus could be described as knowledge of content and students, which includes the knowledge 
that students will form rules and generalisations about mathematics but not all of these will be correct. They also address knowledge of content and teaching, which includes approaches to promoting conflict about those misconceptions that hopefully results in more appropriate conceptions for students.

Nancy Mnolo Chitera, in the article 'Language of learning and teaching in schools: An issue for research in mathematics teacher education', examined the policies which encourage the use of local languages for teaching mathematics and the appropriate support that teachers need to be able to make the transitions from local languages to the formal languages that are commonly used. This includes knowledge of the curriculum, especially the formal terminology and the language that is used to explain mathematical thinking, as well as knowledge of content and students in that the primary goal of the use of local languages is to connect the students' experience more explicitly to the learning of mathematics.

Together, the four articles illustrate examples of the breadth of knowledge that teachers need and the nature of the experiences that might assist teachers in learning that knowledge. They also suggest the importance of ongoing research into processes and experiences that assist teachers in learning that knowledge. They provide evidence of the critical contribution that JMTE makes by offering researchers a forum for sharing with others the products of their thinking and scholarship and research.

In closing, I wish to acknowledge the wonderful contribution made to the journal by the many reviewers who provide readers with assurance of the rigour and quality of the journal contributions. I also thank the four current associate editors, Anne Cockburn, Joao Pedro da Ponte, Margaret Walshaw and Orit Zaslavsky, and previous associate editors Dina Tirosh and Konrad Krainer who were wonderful support for me as editor and no doubt also for Olive in the ongoing development of the journal. I also remember again our wonderful colleague, the late Terry Wood.

\section{References}

Hill, H. C., Ball, D. L., \& Schilling, S. G. (2008). Unpacking pedagogical content knowledge: Conceptualizing and measuring teachers' topic-specific knowledge of students. Journal for Research in Mathematics Education, 39(4), 372-400.

Jaworski, B. (2007). Tasks: A fitting end to an era. Journal of Mathematics Teacher Education, 10(4-6), 201-204.

Shulman, L. S. (1986). Those who understand: Knowledge growth in teaching. Educational Researcher, 15(2), 4-14. 